\title{
Tin Recovery as Stannous Chloride by Chlorination of Tin-Plated Scrap at $298 \mathrm{~K}$
}

\author{
Raul Coltters*, Adalberto Rosales, Aurora Molina \\ Department of Materials Science, Simon Bolivar University, Caracas, Venezuela \\ Email: ${ }^{\text {coltters@gmail.com }}$
}

Received 24 August 2015; accepted 9 September 2015; published 15 September 2015

Copyright (C) 2015 by authors and OALib.

This work is licensed under the Creative Commons Attribution International License (CC BY). http://creativecommons.org/licenses/by/4.0/

(C) (i) Open Access

\begin{abstract}
The chlorination of domestic tin-plated scrap was studied to determine the potential of this material as a source of tin for the manufacture of stannous chloride. It is found that tin-plated crap chlorinated in a preferential manner at a temperature of $298 \mathrm{~K}$ and iron did not react with chlorine at this temperature. It has been demonstrated on a laboratory scale that it is feasible to separate tin from tin coated scrap as high purity $\mathrm{SnCl}_{2}$ crystals by chlorinating in $\mathrm{Cl}_{2} / \mathrm{N}_{2}$ gas mixtures, and as illustrated in Table 3, the $\operatorname{SnCl}_{2}(\mathbf{s})$ obtained in this work has the same high purity that of those produced by some commercial laboratories. The results show that tin-plated scrap has good potential as raw material for the manufacture of stannous chloride by selective chlorination.
\end{abstract}

\section{Keywords}

Chlorination, Scraps, Tinplated, Chlorine

Subject Areas: Analytical Chemistry, Material Experiment

\section{Introduction}

Tin forms two chlorides, stannic chloride $\mathrm{SnCl}_{4}$ and stannous chloride $\mathrm{SnCl}_{2}$, both of which chlorides are of industrial significance [1]. Stannic chloride is primarily used as the starting material for the preparation of other tin compounds [2] and stannous chloride is the principal component of the solution used for the producing electrolytic tinplate, by the Halogen process [3] which became popular in 1942. Stannous chloride is also a component of the solution used for plating the tin-nickel alloy used in the manufacture of printed circuit boards [4]. Large quantities of stannous chloride are used to stabilize the perfume in toilet soaps. Other applications include use as an additive to drilling muds, tin coating of sensitized paper and use as an anti-sludge agent for oils. Because of its reducing properties, it is widely used in many chemical reactions in both synthetic and analytical chemistry [5].

\footnotetext{
${ }^{*}$ Corresponding author.
} 
Anhydrous stannous chloride can be synthesized by a number of methods. Pure stannous chloride can be made by heating stannous sulphide in a stream of hydrogen chloride. Alternatively, stannous hydroxide can be converted to the chloride [5] by reaction with hydrochloric acid. The most straightforward synthesis technique and the one that is most used are the direct reaction of tin metal and either chloride or tin tetrachloride or the reaction of hydrogen chloride gas with tin. Among the more direct methods, the preparation of stannous chloride by the slow addition of chlorine to molten tin is possible but is difficult to control with regard to the simultaneous formation of stannic chloride [6]. Normal practice [6] consists of bubbling chloride through molten tin at $600^{\circ} \mathrm{C}-700^{\circ} \mathrm{C}$ and condensing the stannous chloride at $120^{\circ} \mathrm{C}-260^{\circ} \mathrm{C}$. In all the synthesis procedures used, the stannous chloride must be condensed between $120^{\circ} \mathrm{C}$ and $260^{\circ} \mathrm{C}$ [6] [7]-[13]. Although the suggestion of volatilizing stannous chloride is not new, and in that several processes proposed during the last forty years have been based on this approach, it has not yet been possible to achieve economic success. It is, however, possible to prepare stannous chloride by direct reaction of tin from tin plated scrap with chlorine at room temperature. The basic difference in the chlorination temperature and the direct combination of the elements make this process be the simplest one and economically attractive when compared with the above synthesis procedures at high temperature $\left(200^{\circ} \mathrm{C}\right.$ to $\left.1080^{\circ} \mathrm{C}\right)$ for $\mathrm{SnCl}_{2}$. Information on the kinetics of reaction of tin from tin plated scrap with chlorine gas at room temperature would be useful for determining the conditions under which $\mathrm{SnCl}_{2}(\mathrm{~s})$ forms rapidly.

The kinetics of reaction of tin metal with gaseous chlorine has been reported in the literature [14]-[16], and some information is available on the reaction of tin slags with chlorine [17]-[20] to produce $\mathrm{SnCl}_{2}$. However no systematic studies at low temperatures have been reported in the literature for the chlorination of tin from plated scrap.

From Figure 1, it can be seen that $\mathrm{FeCl}_{2}(\mathrm{~s})$ is more stable than $\mathrm{SnCl}_{2}(\mathrm{~s})$ and $\mathrm{SnCl}_{4}(\mathrm{l})$. However, $\mathrm{SnCl}_{4}(\mathrm{l})$ is highly volatile and apparently, the liquid chloride completely covers the surface of the scrap, so that it is hard to expect that $\mathrm{Fe}$ from the tin cans will react with $\mathrm{Cl}_{2}$.

The compound $\mathrm{SnCl}_{4}(\mathrm{l})$ has a very low melting point of $265 \mathrm{~K}$ and a high vapor pressure of $3.42 \mathrm{KPa}$ at 298 $\mathrm{K}$, as indicated in Table 1. Chlorination to $\mathrm{SnCl}_{4}(\mathrm{l})$ can still be achieved with the high vapor pressure of tin chloride acting as the main driving force.

In the present work, detinning of steel scrap was achieved by selective chlorination in nitrogen-chlorine gas mixtures. Thus, by controlling the partial pressure ratio of $\mathrm{P}_{\mathrm{SnCl}_{4}(1)} / \mathrm{P}_{\mathrm{Cl}_{2}}$ [23]-[27], it is possible to chlorinate selectively the tin from tin plated scrap.

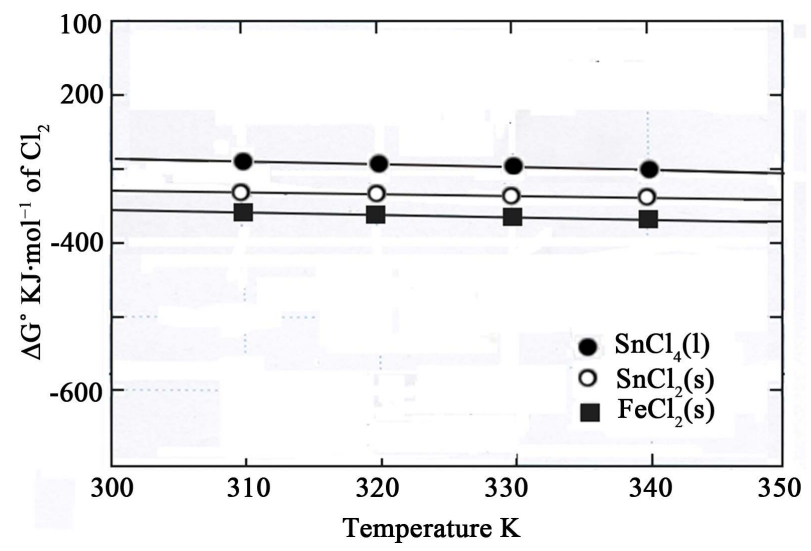

Figure 1. Standard Gibbs free energy as a function of temperature for selected iron and tin chlorides.

Table 1. Thermochemical properties of selected iron and tin chlorides at $298 \mathrm{~K}$ [21].

\begin{tabular}{|c|c|c|c|}
\hline Chloride & Melting point $\mathrm{K}$ & Standard free energy of formation $\Delta \mathrm{G}^{\circ}{ }_{298} \mathrm{KJ} \cdot \mathrm{mol}^{-1}$ of $\mathrm{Cl}_{2}^{-}$ & Vapor pressure at $298 \mathrm{~K} \mathrm{KPa}$ \\
\hline $\mathrm{FeCl}_{2}(\mathrm{~s})$ & 950 & -378.05 & $\approx 10^{-9}[\mathrm{a}]$ \\
\hline $\mathrm{SnCl}_{2}(\mathrm{~s})$ & 520 & -363.77 & $<10^{-5}$ \\
\hline $\mathrm{SnCl}_{4}(\mathrm{l})$ & 240 & -294.20 & 3.42 \\
\hline
\end{tabular}

a. Extrapolated from Barbi et al. data [22]. 


\section{Experimental}

Experiments were carried out with iron scrap (0.5\% Sn) supplied by Domingues \& Cia (Caracas, Venezuela). The experimental arrangement is shown in Figure 2. The reaction tube (25 mm ID) was made of Pyrex. Commercial nitrogen was passed through two drierite desiccants columns to absorb moisture and through heated BASF copper catalyst at $220^{\circ} \mathrm{C}$ and copper turnings at $750^{\circ} \mathrm{C}$ to remove traces of oxygen. Chlorine was dried in three bubblers containing sulfuric acid, and was passed through $\mathrm{P}_{2} \mathrm{O}_{5}$ to remove water. Mixtures of chlorine and nitrogen were prepared by means of conventional calibrated flowmeters. After passing through the reaction tube, the unreacted chlorine was absorbed in concentrated sodium hydroxide solutions. The iron scrap samples were cleaned with xylene and acetone to remove grease. Before each run the samples were weighed to within $\pm 10^{-5}$ grs, and the surface areas used to calculate the reported rates were taken as the geometrical areas of the sample.

To start a run, the samples were inserted in the reaction tube and the system was evacuated by a vacuum pump and back filled with purified nitrogen. After about ten minutes the desired $\mathrm{Cl}_{2} / \mathrm{N}_{2}$ gas mixture was passed through the reaction tube for periods of from two to forty minutes. A run was stopped by introducing purified nitrogen until of the liquid chloride product was removed from the surface of the sample. The sample was then removed from the reaction tube, and subjected to study by X-ray diffraction and chemical analysis for tin content.

\section{Results and Discussion}

Typical variations of the measured weight loss per unit area with time for the chlorination of iron scrap in $\mathrm{Cl}_{2} / \mathrm{N}_{2}$ gas mixtures for two gas flow rates (2.0 and $4.0 \mathrm{mil} / \mathrm{min}$ ) are shown in Figure 3 and Figure 4 . In addition to a fairly significant increase in the rate of tin chlorination with the increase in chlorine partial pressure, the data show two distinguishing features. The first is the extent of increase in tin chlorination with increase in the linear gas flow rate. At a gas flow rate of $4.0 \mathrm{mil} / \mathrm{min}$ one hundred percent conversion is obtained. The second notable feature is that the reaction initially proceeds at a high rate and then decreases rapidly after a few minutes at high conversions. For example 98 percent of conversion is obtained at the initial 10 minutes and one hundred percent of conversion after the next 10 minutes. The variation of the square of the weight of tin chlorinated per unit area with time for three different $\mathrm{Cl}_{2} / \mathrm{N}_{2}$ mixtures is shown in Figure 5 and Figure 6.

The experimental results follow the parabolic law. The observed parabolic rate constants $\mathrm{K}_{\mathrm{p}}$ are given in Table 2 and Figure 7 shows the dependence of the rate constant on the pressure in $\mathrm{Cl}_{2} / \mathrm{N}_{2}$ mixtures. Using the experimental data, it is mathematically possible to represent the results in the form of the following equations at $298 \mathrm{~K}$ and chlorine partial pressure range of $0.25-0.75$ [MPa].

The rate constant increases linearly with the chlorine partial pressure. This result suggests that the chlorination of Tin is probably diffusion controlled at $298 \mathrm{~K}$ and the chlorination then proceeds at a steady state. Also, flow rates of 2 and $4 \mathrm{mil} / \mathrm{min}$ are very low and the dependence of $K_{p}$ on flow rate, as is shown in Figure 7, suggest that, at least with $2 \mathrm{mil} / \mathrm{min}$ the reaction is starved of chlorine. Also it may be that, with flow of $2 \mathrm{mil} / \mathrm{min}$, back diffusion of $\mathrm{SnCl}_{4}$ (g) occurs and prevents the attainment of 100 percent chlorination.

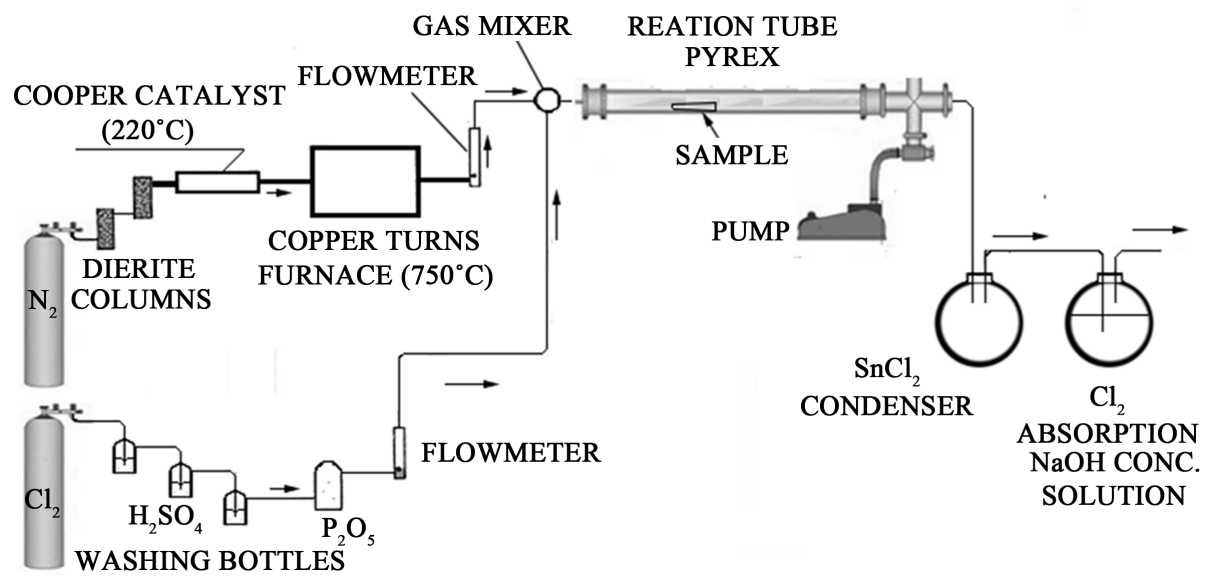

Figure 2. Experimental setup. 


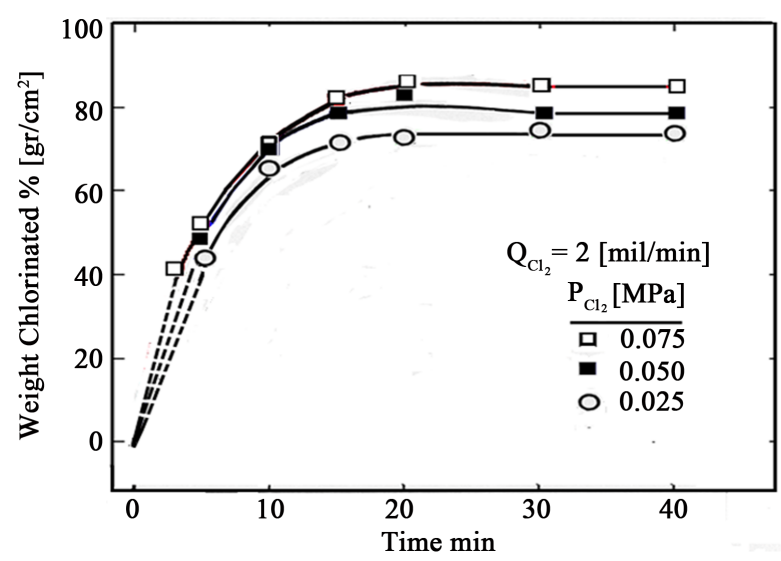

Figure 3. Effect of the partial pressure of chlorine on the tin extraction during chlorination in $\mathrm{N}_{2} / \mathrm{Cl}_{2}$ mixture at $298 \mathrm{~K}$.

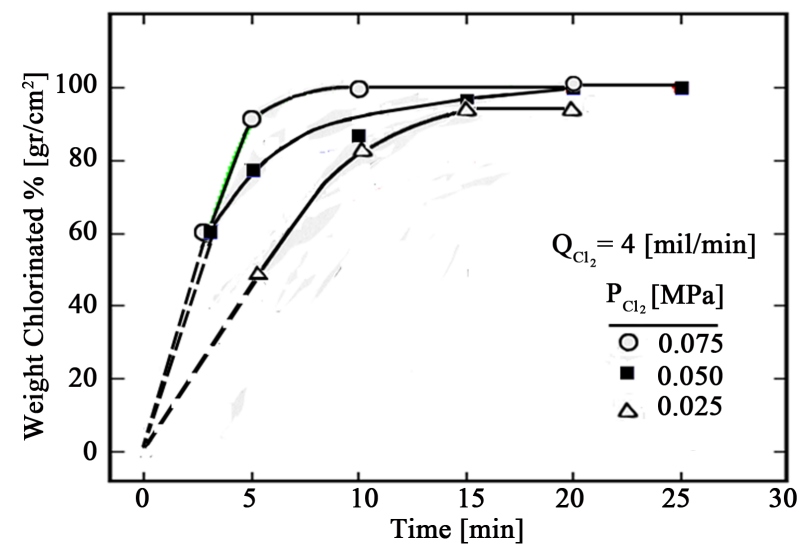

Figure 4. Effect of the partial pressure of chlorine on the tin extraction during chlorination in $\mathrm{N}_{2} / \mathrm{Cl}_{2}$ mixture at $298 \mathrm{~K}$.

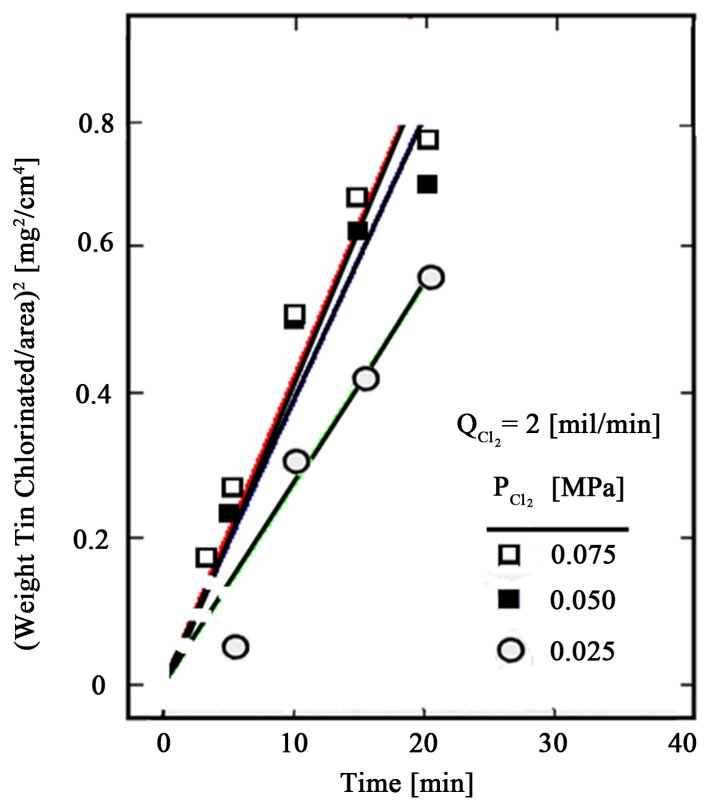

Figure 5. Variation of the parabolic rate constant with chlorine partial pressure at $298 \mathrm{~K}$. 


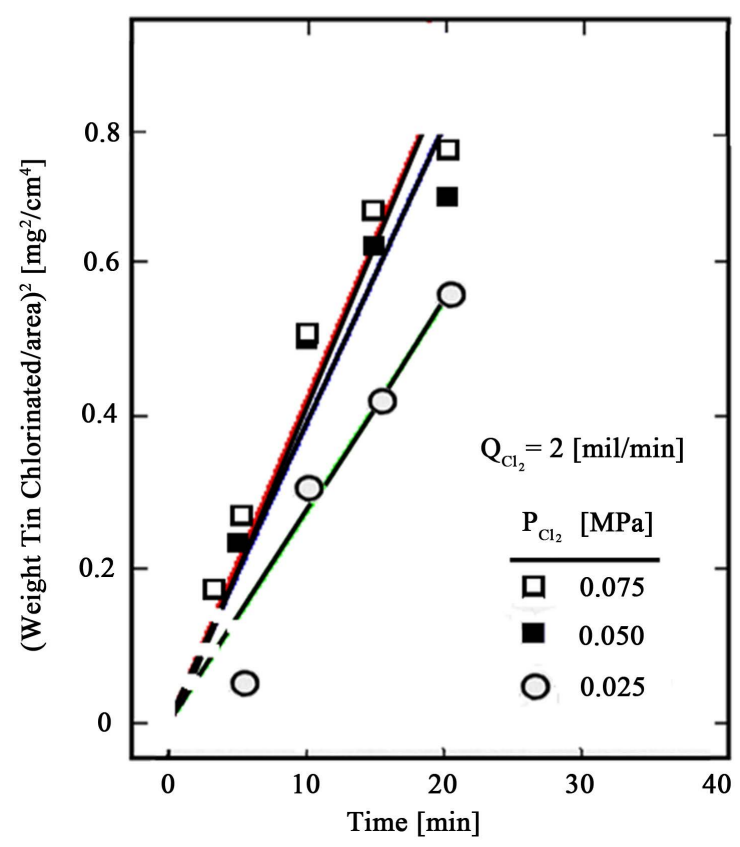

Figure 6. Variation of the parabolic rate constant with chlorine partial pressure at $298 \mathrm{~K}$.

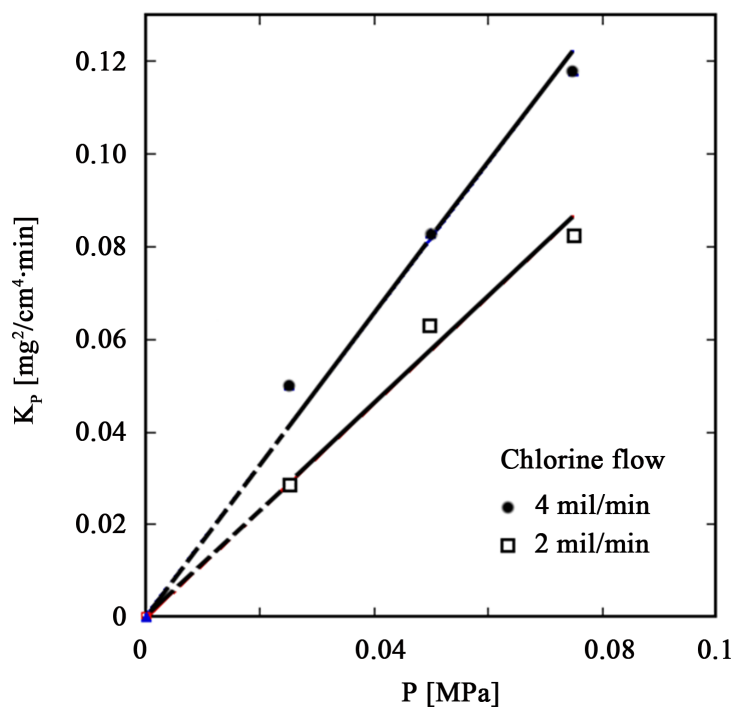

Figure 7. Effect of chlorine partial pressure on the tin chlorination at $298 \mathrm{~K}$.

Table 2. Parabolic rate constant determined for the chlorination of iron scrap at $298 \mathrm{~K}$ under $\mathrm{Cl}_{2}-\mathrm{N}_{2}$ mixtures. Total pressure $0.1[\mathrm{MPa}]$.

\begin{tabular}{cccc}
\hline Gas velocity $[\mathrm{mil} / \mathrm{min}]$ & $P_{\mathrm{Cl}_{2}}[\mathrm{MPa}]$ & Parabolic rate constant $\mathrm{K}_{\mathrm{P}}\left[\mathrm{mg}^{2} / \mathrm{cm}^{2} \mathrm{~min}\right]$ & Correlation coefficient R \\
\hline & 0.025 & 0.028 & 0.986 \\
2 & 0.050 & 0.060 & 0.990 \\
0.075 & 0.082 & 0.989 \\
& 0.025 & 0.045 & 0.991 \\
4 & 0.050 & 0.083 & 0.991 \\
& 0.075 & 0.114 & 0.988 \\
\hline
\end{tabular}




$$
\begin{aligned}
& \text { For } Q=2[\mathrm{mil} / \mathrm{min}] \mathrm{K}_{\mathrm{P}}=8 \times 10^{-4}+1.12 P_{\mathrm{Cl}_{2}} \quad R^{2}=0.995 \\
& \text { For } Q=4[\mathrm{mil} / \mathrm{min}] \mathrm{K}_{\mathrm{P}}=3.5 \times 10^{-3}+1.52 P_{\mathrm{Cl}_{2}} \quad R^{2}=0.993
\end{aligned}
$$

Because of the volatility of the reaction product, no scale is formed and the reaction product sublimes on the walls of the condenser as shown in Figure 8 and along the inner walls of the reaction tube. X-ray analysis of the surfaces of samples and the sublimate white powder were made. The surface of the samples showed no reaction products. Only tin or iron at lower yield and pure iron at one hundred percent yield were found.

Nine samples of the white powder were analyzed by X-ray and UV spectrophotometry. For X-ray analysis, the precipitate was sealed in a glass capillary tube to protect from atmospheric moisture, which was identified as $\mathrm{SnCl}_{2}$ of high purity, as shown in Figure 9 .

Chemical analysis of the metal basis by UV spectrophotometry of the precipitate is showed in Table 3 , the result of chemical analysis validate the X-ray diffraction analysis.

As illustrated in Table 3, the $\mathrm{SnCl}_{2}$ (s) obtained in this work has the same high purity that of those produced by some commercial laboratories [28]-[34].

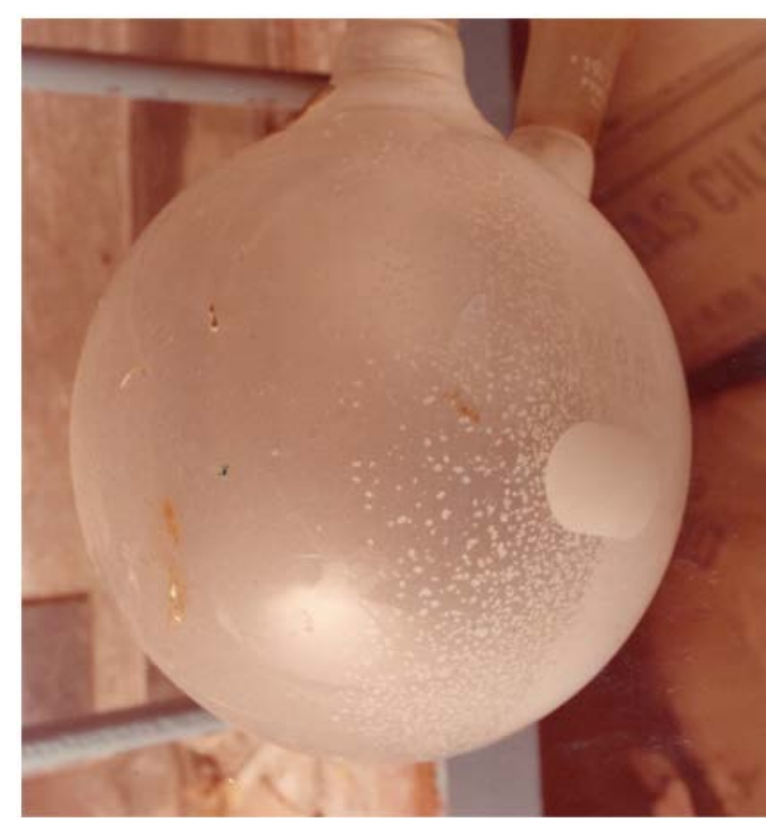

Figure 8. Crystals of $\mathrm{Sn}(\mathrm{II}) \mathrm{Cl}_{2}$ deposited on the inner walls of the condenser.

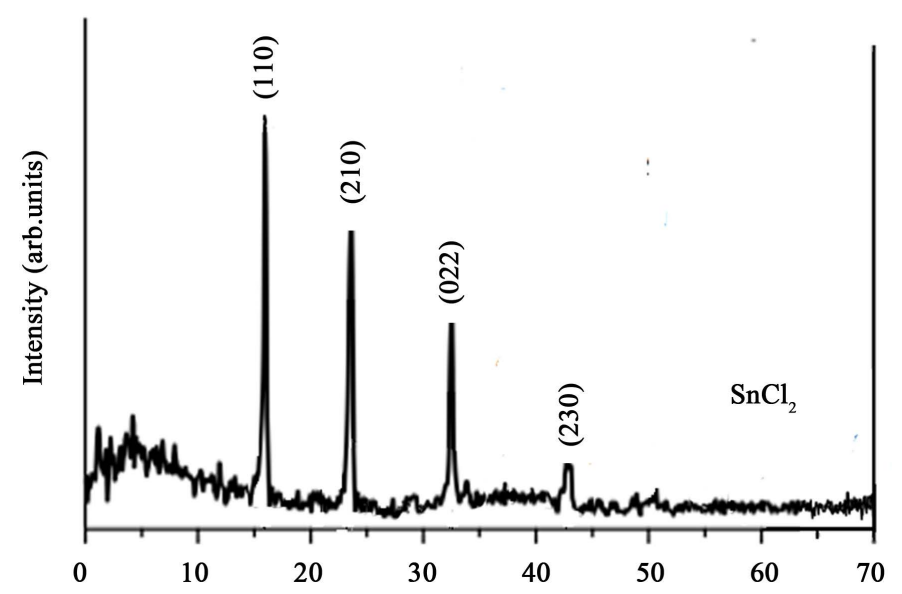

Figure 9. X-ray diffraction pattern of samples of sublimated white powder. 
Table 3. Chemical analysis of metals basis for some commercial Ti(II) chloride.

\begin{tabular}{ccc}
\hline Laboratory & Formula & Tin content \% \\
\hline J. T. Baker & $\mathrm{SnCl}_{2} \cdot 2 \mathrm{H}_{2} \mathrm{O}$ & 56.6 \\
Oxford Chem Serve & $\mathrm{SnCl}_{2} \cdot 2 \mathrm{H}_{2} \mathrm{O}$ & 56.6 \\
Fisher Scientific & $\mathrm{SnCl}_{2} \cdot 2 \mathrm{H}_{2} \mathrm{O}$ & 56.6 \\
Sigma-Aldrich & $\mathrm{SnCl}_{2} \cdot 2 \mathrm{H}_{2} \mathrm{O}$ & 56.6 \\
Sigma-Aldrich & $\mathrm{SnCl}_{2}$ & Trace \\
American Elements Co. & $\mathrm{SnCl}_{2}$ & 62.6 \\
ALS Environmental & $\mathrm{SnCl}_{2}$ & 62.6 \\
Alfa Aesar Johnson M. Co & $\mathrm{SnCl}_{2}$ & 62.6 \\
Tin Content & This Investigation & 62.2 \\
Copper & & 0.002 \\
Iron & & 0.013 \\
Lead & & 0.010 \\
\hline
\end{tabular}

Visual observations made through a cathetometer showed the formation of a transparent liquid film during the reaction, and this liquid film was removed at the end of each run by volatilization into the pure dry nitrogen. Qualitative and quantitative chemical analysis showed that the liquid film was pure $\mathrm{SnCl}_{4}(\mathrm{l})$. No indication of chlorine or stannic chloride reaction with pure iron was found.

The flow rates used correspond to small Reynolds number. Therefore, a laminar flow in the reaction tube was established and a laminar chlorine boundary layer at the surface of the sample is assumed. According to the experimental results, it may be assumed that the chlorination process consists of the following steps:

1) Transfer of chlorine molecules to the sample surface across the laminar boundary.

In this process the rate is flow dependent and increases with the $\mathrm{Cl}_{2}$ content.

2) Formation of liquid products due to a fast chemical reaction on the solid surface.

3) Formation of the volatile products.

4) Transfer of volatile products away from the liquid surface across the laminar boundary layer back to gas stream.

From the proposed mechanism, it would appear that in the initial stages, chlorination occur according to the following reactions.

Liquid film formation

$$
\operatorname{Sn}(\mathrm{s})+2 \mathrm{Cl}_{2}=\mathrm{SnCl}_{4}(\mathrm{l})
$$

and the volatilization process

$$
\mathrm{SnCl}_{4}(\mathrm{l})=\mathrm{SnCl}_{4}(\mathrm{~g})
$$

at the liquid film/gas interface. Then the weight loss of tin is caused mainly by the volatilization of $\mathrm{SnCl}_{4}(\mathrm{l})$ and its diffusion through the chlorine boundary layer.

In the sublimation process from the gas phase, the following equilibria have to be considered

$$
\mathrm{SnCl}_{4}(\mathrm{~g})=\mathrm{SnCl}_{2}(\mathrm{~s})+\mathrm{Cl}_{2}(\mathrm{~g})
$$

The formation of pure $\mathrm{SnCl}_{2}(\mathrm{~s})$ is favored by decreasing the chlorine partial pressure, this happens because the flow of the gas mixture leaving the sample has been depleted free chlorine.

\section{Conclusion}

It has been demonstrated on a laboratory scale that it is feasible to separate tin from tin coated scrap as high purity $\mathrm{SnCl}_{2}$. The experimental results indicate that at the temperature of $298 \mathrm{~K}, P_{\mathrm{Cl}_{2}}$ of 0.75 [MPa] gas flow rate 
of 4 [mil/min] and chlorination time of $12 \mathrm{~min}$ can be achieved at a recovery of $100 \%$. The reaction of tin coated scrap in nitrogen/chlorine gas mixtures, as illustrated by the proposed mechanism, provides unexpected possibilities for the manufacturing industry of advanced inorganic materials, because it provides a very inexpensive method for the manufacture of high purity stannous chloride. This product has many uses in the electronics field [35], for example, as a precursor, from the preparation of high-quality magnetic and semiconducting materials and thermoelectric materials.

\section{Acknowledgements}

The authors are sincerely grateful to Miss. Wang for her help to obtaining financial support for this work.

\section{References}

[1] Steele, D. (1970) The Chemistry of Metallic Elements. Interscience Pergamon Press, New York, 118-119.

[2] Hampel, C.A. and Hawley, G.G., Eds. (1973) The Encyclopedia of Chemistry. Van NostrandReinhol Co., Somerset, N.J.08875-1272.

[3] Hoarse, W.E., Hedges, E.S. and Barry, J.K. (1965) The Technology of Tinplate. St. Martin’s Press, New York

[4] Snell, F.D. and Ettre, L.S., Eds. (1974) Encyclopedia of Industrial Chemical Analysis, Vol. 19. Interscience Pub., New York, 54-73.

[5] Mellor, J.W. (1970) A Comprehensive Trataise on Inorganic Theoretical Chemistry, Vol. VII. Logmar, London, 424436.

[6] Hyatt, D.E. (1974) Preparation of Stannous Chloride. US Patent 3816602 A.

[7] Kanari, N., Mishraa, D., Filippova, L., Diota, F., Mochónb, J. and Allain, E. (2010) Kinetics of Hematite Chlorination with $\mathrm{Cl}_{2}$ and $\mathrm{Cl}_{2}+\mathrm{O}_{2}$ : Part I. Chlorination with $\mathrm{Cl}_{2}$. Thermochimica Acta, 497, 52-59. http://dx.doi.org/10.1016/j.tca.2009.08.007

[8] Tailoka, F., Kumar, R.V. and Fray, D.J. (2003) Mechanism of Chlorination of Tin in Air and Its Application to Steel Can Recycling. Ironmaking and Steelmaking, 30, 391-395. http://dx.doi.org/10.1179/030192303225004033

[9] Tailoka, F., Kumar, R.V. and Fray, D.J. (2003) Removal of Tin from Tin Coated Steel by Chlorination in Air. Ironmaking and Steelmaking, 30, 385-390. http://dx.doi.org/10.1179/030192303225004024

[10] Sokic, M., Ilic, I., Vučković, N. and Markovic, B. (2006) Procedures for Primary Pretreatment and Processing of Waste Tin Plates and Metallic Packages. Acta Metallurgica Slovaca, 12, 354-361.

[11] Dapper, G., Sloterdijk, W. and Vertbraak, C.A. (1978) Removal of Surface Layers from Plated Materials: Upgrading of Scrap. Conservation \& Recycling, 2, 117-121. http://dx.doi.org/10.1016/0361-3658(78)90050-4

[12] Ryosuke, M. and Okabe, T.H. (2005) Iron Removal from Titanium Ore Using Selective Chlorination and Effective Utilization of Chlorine Wastes. Schlesinger, M.E., Ed., EPD Congress 2005, TMS (The Minerals, Metals \& Materials Society).

[13] Fouga, G.G., Pasquevich, D.M. and. Bohe, A.E. (2007) The Kinetics and Mechanism of Selective Iron Chlorination of Ilmenite Ore. Congreso SAM/CONAMET 2007, San Nicolás, 4-7 September 2007, 24-29. http://dx.doi.org/10.1179/174328507x163779

[14] Fruehan, R.J. and Martonik, I.J. (1972) The Rate of Chlorination of Metals and Oxides: Part I. Fe, Ni, and Sn in Chlorine. Metallurgical Transactions, 3, 2585-2592. http://dx.doi.org/10.1007/BF02644233

[15] Lange, N.A. (1967) Handbook of Chemistry. 10th Edition, McGraw-Hill Book Co., New York.

[16] Fruehan, R.J. and Martonik, I.J. (1973) The Rate of Chlorination of Metals and Oxides: Part II. Iron and Nickel in HCL(g). Metallurgical Transactions, 4, 2789-2792. http://dx.doi.org/10.1007/BF02644578

[17] Brochi, E.A. and Moura, F.J. (2008) Chlorination Methods Applied to Recover Refractory Metals from Tin Slags. Minerals Engineering, 21, 150-156. http://dx.doi.org/10.1016/j.mineng.2007.08.011

[18] Nieuwenhius, J.A.M. (1968) Advances in Estractive Metallurgy. Proceedings of Symposium Held in London, 17-20 April 1967, The Institude of Mining and Metallurgy, 44 Podland Place, London.

[19] Jiang, T., Zhang, Y.B., Huang, Z.C., Li, G.H., Guo, Y.F., Yang, Y.B. and Jin, Y.S. (2005) Fundamental Study on Utilization of Tin and Zinc-Baring Iron Concentrate by Selective Chlorination. Transactions of Nonferrous Metals Society of China, 15, 902-907.

[20] Fruehan, R.J. and Martonik, I.J. (1973) The Rate of Chlorination of Metals and Oxides: Part III. The Rate of Chlorination of $\mathrm{Fe}_{2} \mathrm{O}_{3}$ and $\mathrm{NiO}$ in $\mathrm{Cl}_{2}$ and HCL. Metallurgical Transactions, 4, 2793-2797. http://dx.doi.org/10.1007/BF02644579 
[21] Barin, I., Knacke, O. and Kubaschewski, O. (1973) Thermochemical Properties of Inorganic Substances. SpringerVerlag, Berlin.

[22] Bardi, G., Brunetti, B. and Piacente, V. (1996) Vapor Pressure and Standard Enthalpies of Sublimation of Iron Difluoride, Iron Dichloride and Iron Dibromide. Journal of Chemical \& Engineering Data, 41, 14-20. http://dx.doi.org/10.1021/je950115w

[23] Jeffes, J.H.E. (1968) The Physical Chemistry of Transport Prrocesses. Journal of Crystal Growth, 3, 13-32. http://dx.doi.org/10.1016/0022-0248(68)90098-5

[24] Kaye, G.W.C. and Laby, T.H. (1995) Tables of Physical \& Chemical Constants. 16th Edition, NPL (National Physical Laboratory).

[25] Jeffes, H.E. and Alcock, C.B. (1968) The Production of Refractory Crystals by Vapor Transport Reactions. Journal of Materials Science, 3, 635-642. http://dx.doi.org/10.1007/BF00757911

[26] Jeffes, H.E. (1972) The Thermodynamics of Chemical of Transport Reactions with Special Reference to the Tantalum Iodine. Journal of Crystal Growth, 17, 46-52. http://dx.doi.org/10.1016/0022-0248(72)90230-8

[27] Krabbes, G., Oppermann, H. and Wolf, E. (1968) Application of Thermodynamics Models to Chemical Transport Reactions with Systems Containing Several Coexisting Solid Phases with a Homogeneity Range. Journal of Crystal Growth, 64, 353-366. http://dx.doi.org/10.1016/0022-0248(83)90144-6

[28] J.T. Baker. https://www.avantormaterials.com/Products/Brands/J-T-Baker.aspx

[29] Oxford ChemServe Co. http://oxfordchemserve.com

[30] Fisher Scientific. https://www.fishersci.com

[31] Sigma-Aldrich. http://www.sigmaaldrich.com/technical-service-home/product-catalog.htm

[32] American Elements Co. https://www.americanelements.com/chemicals.html

[33] Chemicalland21. http://www.gfschemicals.com/statics/

[34] Alfa Aesar Johnson M. Co. https://www.alfa.com/en/docs/InorganicCatalog.pdf

[35] Cusak P. (2011) ITRI Chemical Technology Overview. ITRI Limited, St Albans. https://www.itri.co.uk/index.php?...att 